\title{
Creative noise: considerations of sound design for public interventions
}

\author{
$>$ Luciana Roça \\ University of São Paulo, Brazil \\ lucianaroca@usp.br
}

\author{
> Marcelo Tramontano \\ University of São Paulo, Brazil \\ tramont@sc.usp.br
}

\begin{abstract}
Despite the interpretations of noise as a disturbance, interference or an unpleasant sound, noise is deeply related to cultural and social processes. This paper aims to discuss the use of non-musical sounds in public artistic interventions, based on a sound intervention conducted as part of an accomplished research, focusing the juxtaposition of sound and physical environments by the use of sound interfaces providing collective listening in public spaces. This research is also part of Nomads.usp, Centre of Interactive Living Studies, of the Institute of Architecture and Urbanism at the University of São Paulo.
\end{abstract}

Keywords: sound environment; urban intervention; public space; sound design; noise

\section{Introduction}

Noise is often related to disturbance, annoyance or informally referred as a particular non-musical or non-desirable sound. Despite of this fact, sounds are attached to cultural and social processes regarding not only listening, but practices as well. If silence is considered the complete absence of sounds, it exists only when there is a lack of matter, complete deafness or death, as John Cage (1961) argues. Sound is related to movement, ways of living, culture, urbanism, effects of technology and social aspects can be reflected in the sound environment.

Obviously, high intensity noises have been an issue in several cities of the world. Even though this paper has a different approach, considering noise as a reflect of our own actions, arrangements and dynamics in space and as a holder of imaginative interpretation and representation. The ambiguous nature of the meaning of "noise" and its use in public interventions is discussed in this paper, taking into account the results and understandings of the urban intervention "Urban Reverberation" and its theoretical contributions approaching Urbanism, Architecture and Sound Studies.

This research is part of Nomads.usp, which has interdisciplinary researches with theoretical and practical approach. This paper is also a result of the Public Policy Project "Hybrid Territories: digital media, communities and cultural actions", funded by São Paulo State Agency for Research Funding.

We consider urban intervention as an intended change in the current urban context, which may be ephemeral or long-standing. Thus, interventions establish a contextualized relationship with the city, holding the attention to its complexities, conflicts, potentials and qualities which may not be noticed in daily life.

The most direct relational aspect between sound and space is found in its acoustical characteristics: physical space interferes with sound through Physics. Beyond that, considering space as formed by its physical objects and its actions in an interdependent process (Santos, 2001), sound not only reflects space activities but also and may affect the aprehension oneself has of the space. The comprehension given by the sound environment is juxtaposed to other characteristics of space and, according to LaBelle (2006), in a relational interplay.

From this perspective, there are cultural and social matters on listening to the cities. Every neighborhood has its own particularities, sound elements and context. Having this in mind, the intervention "Urban Reverberation" consists in the relocation of train's sounds into a square located at the commerce center of São Carlos, São Paulo State, Brazil. The locations addressed by the intervention were a peripheral neighborhood, the social housing complex Waldomiro Lobbe Sobrinho, called CDHU by city dwellers, and the Municipal Market Square, located at the commercial centre of the city.

The train is part of historical and current context in this city and nowadays the railroad is only used for cargo transportation. The railroad had a great role on the city development in the first half of 20 th century. Until today the railroad crosses the city and is present in the daily life of several people who lives nearby. Thus, in the sound intervention the train's sounds had its meanings altered by the exchange of context as well as the comprehension of the 
public square itself, giving rise to many different interpretations of sound's meaning associated with the space of the public square.

The paper discusses the importance of sound and noise as a holder of representative, socio, cultural potential in the context of the intervention and the experiment. Methods and its contributions are presented. Then, regarding these aspects, the paper also debates that sound design for public interventions considering not just sound, or "noise", but also sound environment, physical space, interfaces and in situ context as an interdependent whole.

\section{Sound ambiguities}

Sound, being a result of our movements, dynamics and ways of living, has a cultural and social importance and has diverse meanings among people. As Raimbault and Dubois (2005) argue the consequences of the intensity of sound due to traffic may be lower than the consequences of intended entertainment: the difference resides in the cultural value given to the activity. The unavoidable and intention seems an of the origins of the ambiguous nature of "sound" and "noise".

Truax (2001) discusses that sound has a mediating effect between individuals and their environment, reinforcing the importance of communication, and noise is a source of negative mediation since it makes the communication with the environment more difficult. However, in certain situations sound can have a role and be representative even in these situations.

Regarding public artistic interventions and ways of explore non-musical sound in qualitative forms, the relationship between sound and context may encourage the listener to argue and question established situations. Consequently, the noise has been discussed in many perspectives related to music or art. As Douglas Kahn (1999, p.21) comments: "with so much attendant on noise it quickly becomes evident that noises are too significant to be noises".

Noise does not exists in itself, as Attali (1985, p. 26) argues based on information theory to begin his discussion, and this background can be extended. Noise only exists within a system, related to something else.

Noise is often considered as an unwelcome signal in a system, however Abraham Moles (1968 apud Russo, Warner, 1987) expands its limits by considering will of the receiver: it is the sound we do not want to hear, the signal we try to eliminate.

There is no absolute structural difference between noise and signal. They are of the same nature. The only difference which can be logically established between them is based exclusively on the concept of intent on the part of the transmitter. (Moles, 1966, p. 78)

Therefore in this perspective a cultural perception of noise is considered, within a broader system. Noise exists within a system and related to someone. But since it is related to cultural perception, context also exists and, consequently, the interpretation of sound.

In addition to this, noise may also be considered as a source of mutation; in case the system does not have sufficient standards or rules to regulate it, noise can be a source of change. On the one hand noise attacks the system which may be transformed or destroyed; on the other hand noise is an input to exploring new paths.
The absence of meaning, as we have said, is nonsense; but it is also the possibility of any and all meanings. If an excess of life is death, then noise is life, and the destruction of the old codes in the [musical] commodity is perhaps the necessary condition for real creativity. No longer having to say anything in a specific language is a necessary condition for slavery, but also of the emergence of cultural subversion. (Attali, 1985, p. 122)

As Attali (1985) argues, noise actually also creates meaning; the signal interruption means a critic or prohibition and at the same time the lack of meaning gives place to other meanings to arise. In public spaces, silence is also absence, it denounces the misuse

Besides its subversive character, noise may repress important meanings which inhabit the same system. More ambiguities establishes considering

[...] noise does indeed exist, and trying to define it in a unifying manner across the range of contexts will only invite noise on itself. Suppressing noise only contributes to its tenacity and detracts from investigating complex means through which noise itself is suppressed, while celebrating noise easily becomes a tactic of suppressing something else. (Kahn, 1999, p.21)

Noise is multifaceted and comes as an ambiguous category which is socially defined and is in constant renegotiation, depending on a system and also cultural and social context. The distinction between signal and noise, regarding sound environments, is much more relative than absolute.

As objects and images that fills the visual field, sounds fills hearing, combine with each other, obtain meanings. Then, noises are not just a sound between many others: noises are a set of sound powers which may establish differential relations and may transpose its first condition, as meaningless, and be a basis of a signifying sound.

Meanings are given by composition and design, and the subversive character of noise is to be a raw material to the creation of sense.

\section{Listening inside the context}

The process given by recording, editing and reproducing a certain sound in a different location is considered a relocation instead of dislocation. According to Simon Emmerson (2012), the term dislocation in English language is used as a negative action, meaning "not where it should be", "something that needs correcting". In this research we transpose these affirmations to the context of the sound intervention "Urban Reverberation".

An intervention is always inscribed in a wider and more complex context, which is the urban flow (Peixoto, 1998). Keeping this in mind, "Urban Reverberation" recontextualises sound causing a breach of expectation and is notable to highlight that the sound is in dialogue with the context of the city. Sound gathers different meanings by the exchange of its context, not implying loss of meaning. Thus, sound is recontextualised; despite being a breach it is inscribed in a broader context in which the reproduced sound encounters other situations and brings together other qualities.

In order to arrange these aspects to the intervention, the need to address invisible qualities of space, its context and dynamics to the intervention was noticed since its conception. Therefore, minding 
the railway which crosses the city of São Carlos and its given effect on city dwellers at the CDHU, the set of train's sounds the chosen approach as it deals with historical and social aspects of the city.

"Urban Reverberation" worked with two distinct locations: the Municipal Market Square at the commercial centre of the city, and social housing complex Waldomiro Lobbe Sobrinho, popularly called CDHU.

The Municipal Market Square is used by pedestrians as a passage and its cycles of activity are clearly determined by shopping hours. Although the square does not have many public equipment for common use, many people uses the square as a meeting point, specially retired people and consumers of various age groups.

The cargo trains cross the city several times, at day and night. The CDHU is a peripheral neighborhood area where almost a thousand families live, closely located to the railway. By the time of this research, the researchers of Nomads.usp already had an approach to this community due to the project "Hybrid Territories" (Nomads. usp, 2013). This approach facilitated the understanding of the issues given by the train and its sounds, and also other elements of the sound environment of the area related by the dwellers of the CDHU.

\section{Methods}

First, it was made a study about the sound environments so it could be more understood by the researchers. Regarding its methods, a soundwalk was made in both locations addressed by the intervention. Soundwalk is a known method in the Sound Studies field of study, can be considered as a structured observation method for investigating sound environments. To sum up, the researcher walks through a defined path several times in different schedules, records its sound with appropriated equipment and takes photos or records a video, and then the material is analyzed (Semidor, 2006). Thus, the method can cover a broad area and also offers the possibility to record the sound as a pedestrian. Furthermore, we consider soundwalk as a valuable method to understand the activities and rhythm of the location.

As a result of this first part of the experiment is argued that even when the sound environment of two locations seems very similar it has its particularities, given not only by its physical space but

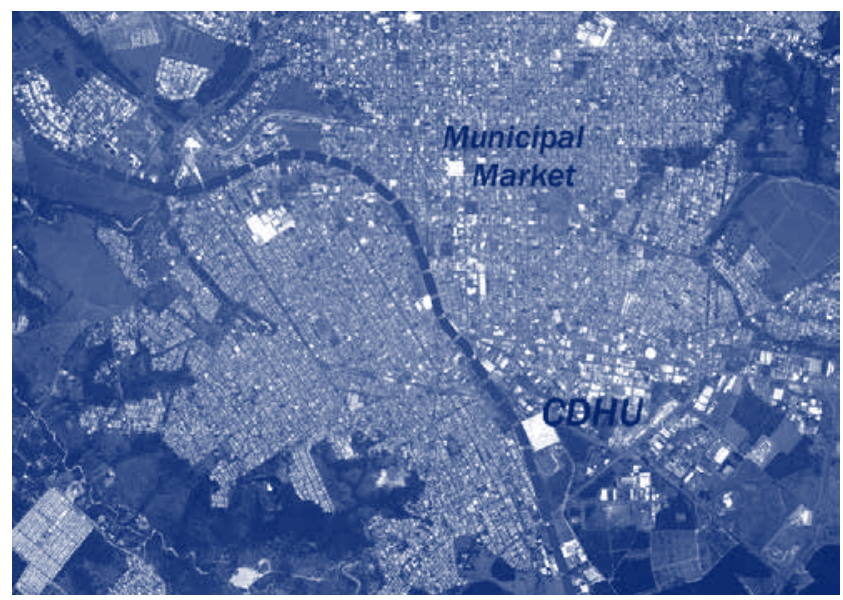

Figure 1: The south-central area of São Carlos, the locations of the Municipal Market and $\mathrm{CDHU}$ and the dashed line refers to the railroad path. Image from Google Maps and modifications by the authors. also by its use. It reinforces the reasoning given by Henri Lefebvre (2004) that neighborhoods have different cycles and rhythms which reflect the social organization of the space.

These aspects contributes to the intervention as a whole, and also leads to the understanding of sound, many times referred as "noise", as a holder of representative potential which may change the comprehension of the space.

The train was recorded several times in order to relocate the sound. The audio was edited so it could be spatialized, suggesting a passage of an actual train at the square.

During the intervention, semi-structured interviews were conducted, video recordings and photos as well. The interviews helped to get direct access to the opinions of present people and their interpretation. The interviews gathered a broad mosaic of different comprehensions, from annoyance and disturbance to affective memories and enjoyment. The relocation also brought people's attention to the equipment, associating vision to the context.

\section{Giving meanings to noise}

In Portuguese, the word "barulho" can be translated to English as noise. Its origin is uncertain but it is often referred as non-musical sound, rumor, and agitation. Despite this fact, it also has meaning as a sound which is undesirable and unpleasant just as noise in English. The word barulho is said very often in the intervieweds' comments, as a colloquial form to say "sound".

Ruido, also translated as noise, can be considered as antonymous of signal. No interviewed said "ruido", even when describing the sound as "noisy" or saying the sound was "bothering" them.

The set of train's sounds promotes change of focus and attention of the listening process. People face another sonic situation which is uncommon to that local and, in order to identify what and why is listened, a process of an attentive and engaged listening. As a representative element, the train's sounds encourage listening as an active practice.

The relocated sound had an affective action of sound on some interviewed listeners. Some comments also demonstrate associations between the intervention and the listener's home, which denotes the intervention as a form of the listener perceive his/her own context. On the other hand, it is also noticeable the estrangement to the situation in some comments.

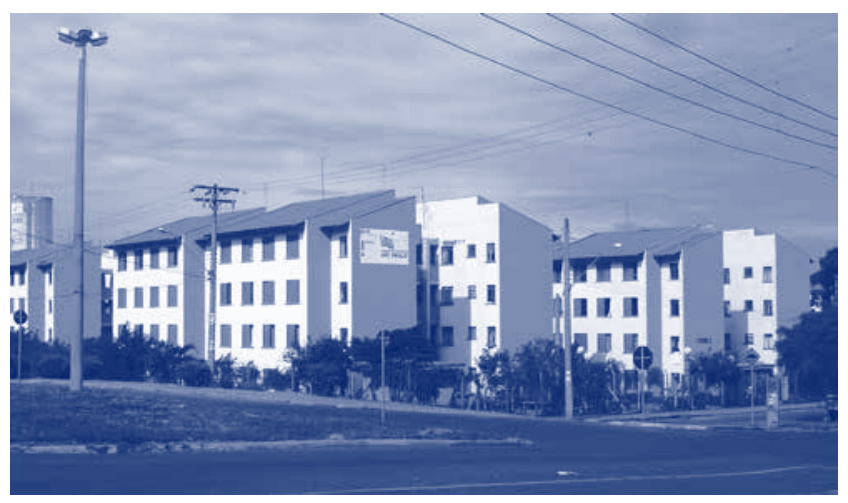

Figure 2: The social housing complex Waldomiro Lobbe Sobrinho, "CDHU". Photo by Nomads.usp. 
Considering qualitatively the set of train's sound and promoting estrangements due the difference in relation to daily sound environment, the intervention led listeners to question these contexts. Thus, reproduction brings forth common issues of several city dwellers; it inserts aspects related to the daily routine through differentiation of context and sound environment. Thus, the train's sounds become a convergent point encouraging varied discussions and understandings, which may be externalized or not.

\section{Findings}

The set of train's sounds, recorded and edited, yields a sound environment with virtual instances. The square's sound environment which has direct relationship with actions of space meets another sound environment and both are juxtaposed.

The loudspeaker has, in effect, allowed us to set up a virtual acoustic space into which we may project an image of any real existing acoustic space, and the existence of this virtual acoustic space presents us with new creative possibilities. (Wishart, 1996, p. 136)

The virtual sound environment given by the process of recording, editing and reproduction is juxtaposed and its result is a hybrid sound environment. It is not an adornment or adjunct since it brings forth questions and understandings which would not be possible at the location without an intervention, e.g. the effect the railroad has in the city. The recontextualised set of train's sounds offer propositions of understandings. The relationship between hybrid sound environment and context suggests meanings and removes randomness.

The relationship between sound environments and space, recontextualises and is a composition formed by sound and space. The sounds, 'noises', acquire a representative value and become meaningful by the switch of context. Communication channels among people, context, sound and space are set up, considering space not only its physical instances but as well its dynamics. The context is also formed by each one personal experience, and it can

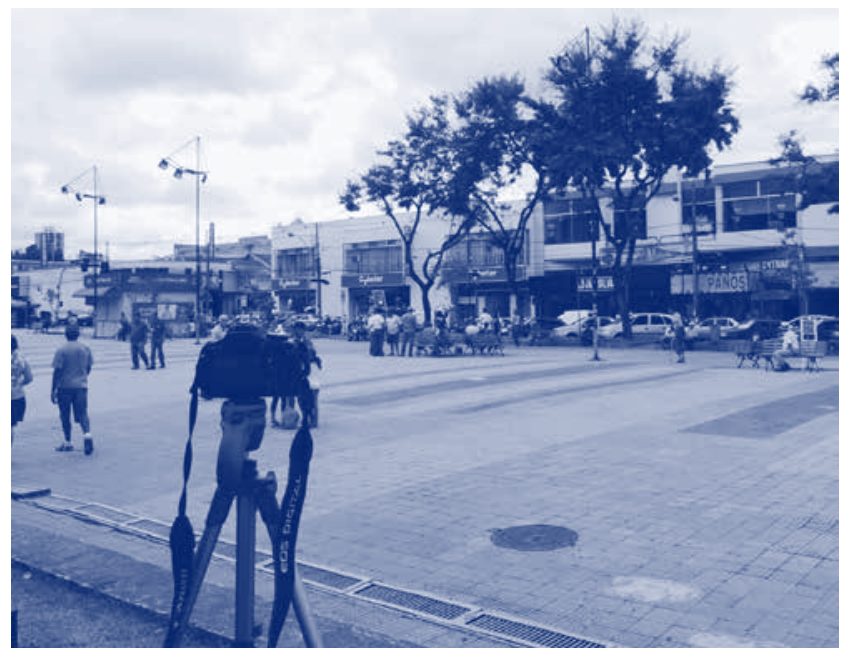

Figure 3: Camera recording video at the Municipal Market Square while the intervention was occurring. Photo by Nomads.usp. be noticed on many comments regarding their own history, ways of living and experiences.

Accordingly to "Urban Reverberation" intervention's experience is possible to argue: "The aleatory then rejoins order. Any noise, when two people decide to invest their imaginary and their desire in it, becomes a potential relationship, future order." (Attali, 1985, p. 143).

The whole consisted by physical space, spatial dynamics and context, sound environment and listening engagement fosters the representative effect of sound. Sound is related to listener's previous experiences, not only related to sound. Thus, the use of non-musical, unpleasant sounds or sound that seems unrelated to certain location, establishes many different understandings and interpretations, also founding a communication locus, suggesting a theme to be discussed in public spaces. In addition to this, the juxtaposition between physical and sound environments gives meanings to noises, favoring different comprehensions of space - but the link with the context must not be forgotten.

\section{Acknowledgments}

We thank to the São Paulo State Agency for Research Funding (FAPESP) for supporting the development of this research and all the participants of the intervention "Urban Reverberation".

\section{References}

Attali, J. (1985). Noise: the political economy of music. Minneapolis: University of Minnesota Press.

Cage, J. (1961). Silence. Middletown: Wesleyan University Press.

Emmerson, S. (2012). Location - Dislocation - Relocation ('Where is Live Electronic Music?'). In: Proceedings of IV Seminário de Música, Ciência e Tecnologia: Fronteiras e Rupturas, São Paulo.

Kahn, D. (1999). Noise, water, meat: a history of sound in the arts. Cambridge: MIT Press.

LaBelle, B. (2006). Background noise: perspectives on sound art. New York: Continuum International Publishing.

Lefebvre, H. (2004). Rhythmanalisys: Space, time and everyday life. London: Continuum Books.

Moles, A. (1966). Information Theory and Esthetic Perception. University of Illinois Press.

Nomads.usp (Ed.). (2013). Territórios Híbridos: Ações culturais, espaço público e meios digitais. São Carlos: IAUUSP.

Peixoto, N. B. (1998). Intervençóes urbanas: Arte/cidade. São Paulo: Editora Senac.

Raimbault, M., Dubois, D. Urban Soundscapes: Experiences and Knowledge. Cities, v. 22, n. 5, p. 339-350. doi:10.1016/j. cities.2005.05.003

Russo, M.; Warner, D. Rough Music, Futurism and Postpunk Industrial Noise Bands. Discourse, v.10, n.1, p. 55-76, 1987. Retrieved from http://www.jstor.org/stable/41389097.

Santos, M. (1996). A natureza do espaço. Sáo Paulo: Hucitec.

Semidor, C. (2006). Listening to a city with the soundwalk method. Acta Acustica united with acustica, v. 92, n. 6, p. 959-964.

Truax, B. (2001). Acoustic Communication. Westport: Ablex Publishing.

Wishart, T. (1996). On Sonic Art. Amsterdam: Harwood Academic Publishers GmbH. 